\title{
Designing of $\mathrm{SnO}_{2}$ Nanostructured-based Sensors with Tailored Selectivity Toward Propanol and Ethanol Vapors
}

Rapelang G. Motsoeneng ${ }^{1,2}$, Ioannis Kortidis ${ }^{1,2}$, Suprakas Sinha Ray ${ }^{1,2^{*}}$, David E. Motaung ${ }^{1,3^{*}}$

${ }^{1}$ CSIR National Centre for Nano-structured Material, Council for Scientific Industrial Research, Pretoria, 0001, South Africa

${ }^{2}$ Department of Applied Chemistry, University of Johannesburg, Doornfontein, Johannesburg, Gauteng, South Africa

${ }^{3}$ Department of Physics, University of the Free State, P.O. Box 339, Bloemfontein ZA9300, South Africa
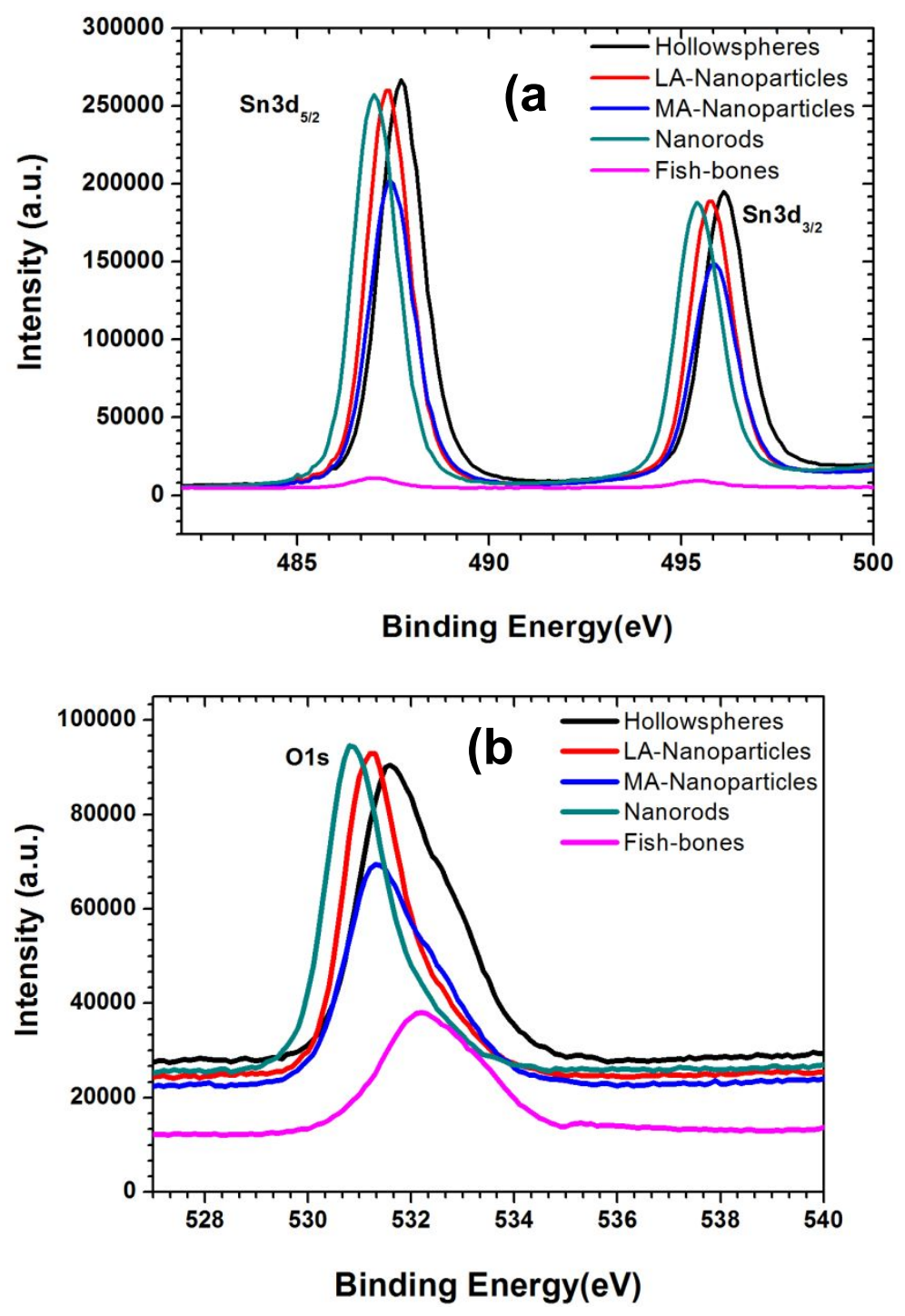

Figure S1. (a) Sn3d peaks and (b) O1s peaks of various SnO2 nanostructures 


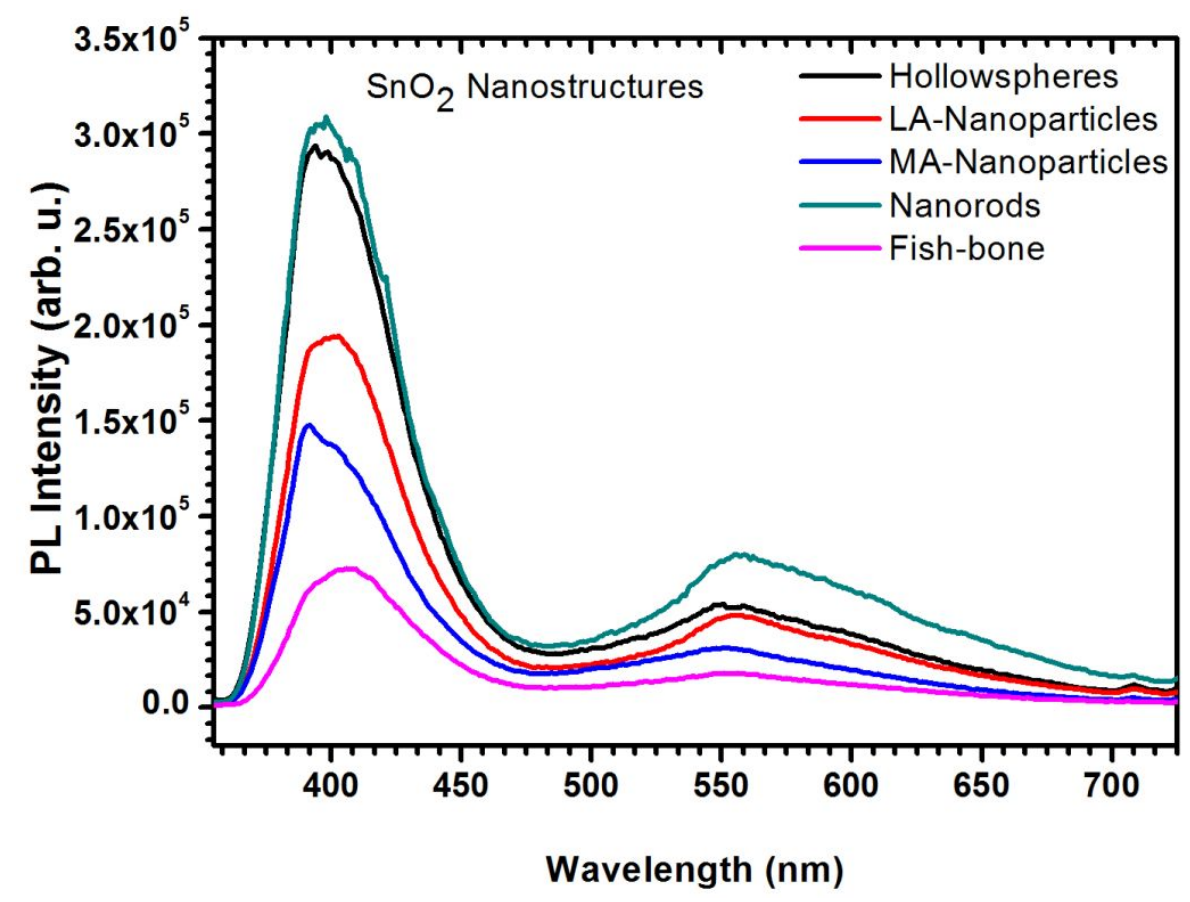

Figure S2. $\mathrm{PL}$ Spectra of various $\mathrm{SnO} 2$ nanostructures. 